\title{
Earth Observation System-Based Impact Assessment of 2012 Flood in Delta State Nigeria
}

\author{
AHUCHAOGU UDO. E ${ }^{1}$, OJINNAKA O. C. ${ }^{2}$, NJOKU R. E ${ }^{3}$, BAYWOOD C.N ${ }^{4}$ \\ 1,3,4, Department Of Surveying And Geo-Informatics Federal University Of Technology Owerri \\ ${ }^{2}$ Department Of Geo-informatics, And Surveying, University Of Nigeria, Enugu Campus
}

\begin{abstract}
Flooding is one of the most serious natural hazards in the world. It has become a common natural disaster which has claimed many lives, displaced millions and resulted to the destruction of properties and degradation of contiguous farmland. Though over the decades the people of Delta state have had to contend with sporadic overflows from the river but not in the scale of 2012 flood event. Flood in 2012, submerged coastal villages, displaced millions of people, submerged several square kilometers of land, disrupt economic activities and properties worth of millions of naira was lost. This study was provoked based on the fact that since the disaster, no reliable investigation and inventory has been made as a guide for mitigation for future occurrence. Currently Earth observing system (EOS) is gaining popularity in solving many environmental problems due to its accurate and timely delivery of information required for decision making. Therefore the aim of this study was to determine the impact of 2012 flood in delta state. Pre-flood and flood imageries captured by and Moderate Resolution Imaging Spectroradiometre (MODIS), Land sat imagery with resolution 30m, SRTM with resolution 30 arc second, questionnaire, interview, Global positioning system (GPS) and geographic information system (GIS) was used for data collection and analysis. The map generated from the non-flood image captured on 20th October 2010 was used as a reference to determine the extent of flooding from the disaster image. Spatial impact was determined based on the extent of the submerged land territory while physical economic impact was measured based on property damages. This study revealed that a total landed area of $2185 \mathrm{Sq} . \mathrm{kms}$ was covered by flood excluding the original extent of the river. Further assessment revealed that 785000 people were affected, crops worth's 3.1 billion naira were destroyed, 231 communities in 12 local government of the 25 local government areas were adversely affected these include 118 communities market, 743 market stalls, 220 primary schools, 84 secondary schools, 435 fish farms, 526 poultry farms, 58 piggeries and 5099 houses.
\end{abstract}

Keywords: key words, MODIS, SRTM, Flood, Hazard, Imagery

DOI: $10.7176 / \mathrm{CER} / 12-9-08$

Publication date:September 30th 2020

\section{Introduction}

Flooding is one of the serious natural hazards in the world (Emmanuel et al, 2015). It has become a common natural disaster which has claimed many lives, displaced millions and resulted to the destruction of properties and degradation of con-tiguous farmlands. (Nkeki 2013). Flooding is defined as a large amount of water covering an area that was usually dry (Olajuyigbe et al., 2012). Nwafor (2006) defined flood as a natural hazard like drought and desertification which occurs as an extreme hydrological (runoff) event. The impact of floods has been increased due to a number of factors, including rising sea level and increased developments on flood plain etc. (Ologunorisa, 2004). Flooding sometimes results when inflow makes a stream channel exceeds its caring capacity and also when there is low infiltration capacity, poor drainage, collapse of hydrological structures such as dams and when there is heavy rainfall. In the period 1963 to 1992, the world suffered from 202 floods with more than $1,000,000$ ( one million) victims, most of them are flash flood recorded as torrential rains, monsoon floods, headwater flood or landslide (Kwak, and Kondoh, 2008)). The largest flood catastrophe on the list was the flash flood in June 1991 with more than 5,000 victims in Afghanistan (Ramnoop, I995 and Inyangorok, 2011) Over the decades the people of Delta state have had to contend with sporadic overflows from the river but not in the scale of what happened in 2012. Flood in 2012 submerged coastal villages. Residence in some communities complained that they woke up early in the morning only to observe that flood has covered the entire places. The havoc wreaked by the water on the communities is un-usual and sympathetic and accounted for a large proportion of loses. Properties worth of millions of naira were lost. People were prone and were infected with deadly diseases. All sectors of the economy were affected and deadly reptiles like crocodile, snakes etc dislodged by the rampaging flood was seen as threat to the communities. Though the flood disaster of 2012 in Nigeria was a national calamity, Delta state was one of the worst hit belonging to category ' $\mathrm{A}$ ' in the federal government impact assessment rating (IAR). Figure1 is scenario created by flood in 2012 in the study area. The use of earth observation system (EOS) 
technology and GIS platform has become an integrated, well developed and reliable approach in flood disaster and risk management. (Nkeki 2013). The application of geospatial technologies (Remote sensing and GIS) in analysis and management of spatial information is gaining popularity in recent times. It provides information that has proved useful for a wide range of application in disaster management. In the advanced cases of GIS the data is being collected from satellite and then integrated with high computers so that the data can be visualized, analyzed, manipulated, enhanced and stored as data reference to earth. (Owais Bashir et al's 2019). The potential of GIS, when combined with Remote sensing satellite image provides a very flexible platform for modeling and analysis of any environmental phenomenon and also provides sustainable and profitable solutions to environmental management (Ejikeme2015 ). The evaluation and management of floods constitute the first step and the rational basis of mitigation measures against flood damages. Geospatial techniques have been proved to be the most effective tool for flood analysis. The use of remote sensing and GIS techniques for flood mapping and monitoring is an important tool of information for decision-makers.

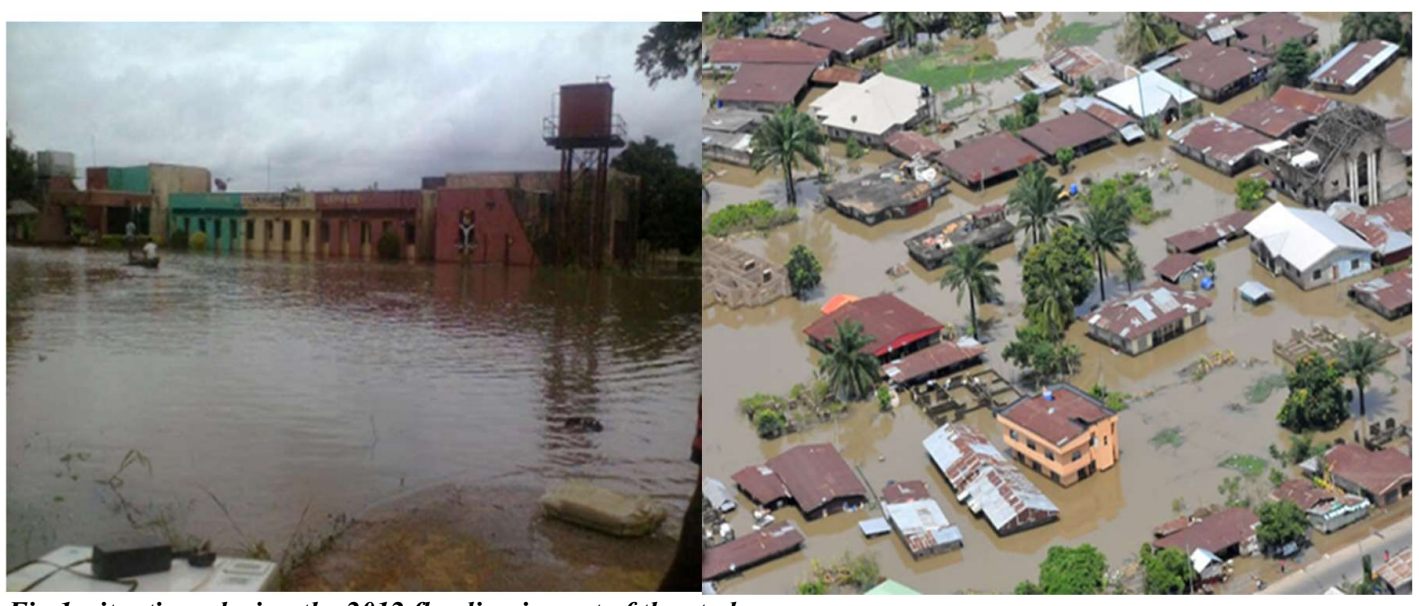

Fig 1. situations during the 2012 flooding in part of the study area

\subsection{Aim and Objectives}

The aim of this study is to determine the impact of 2012 flood in the study area

\section{Objectives}

$>$ To determine the spatial impact of 2012 flood within the study area

$>$ To understand influence of topography to spatial spread

$>$ To determine the facilities that was affected

$>$ To determine the most affected land use type

\subsection{Study Area:}

Delta state is one of the oil producing state in Nigeria located in the south-south geo-political zone in the region known as Niger Delta. It has a population of 4098391 comprising of 2074306 males and 2024085 females base on 2006 population census. The State presently cover a land mass of $17530 \mathrm{~km}^{2}$ and is bounded in the North by Edo State, the east by Anambra State, south east by Bayelsa State. Geographically it is located between latitude $5^{0} 00$ and $6^{0} 30^{\prime}$ and between longitude $5^{\circ} 00^{\prime}$ and $7^{\circ} 00^{\prime}$. Delta State is generally low lying area without remarkable hills and has a wide coastal belt interface with rivulets and streams which forms part of the Niger Delta. 


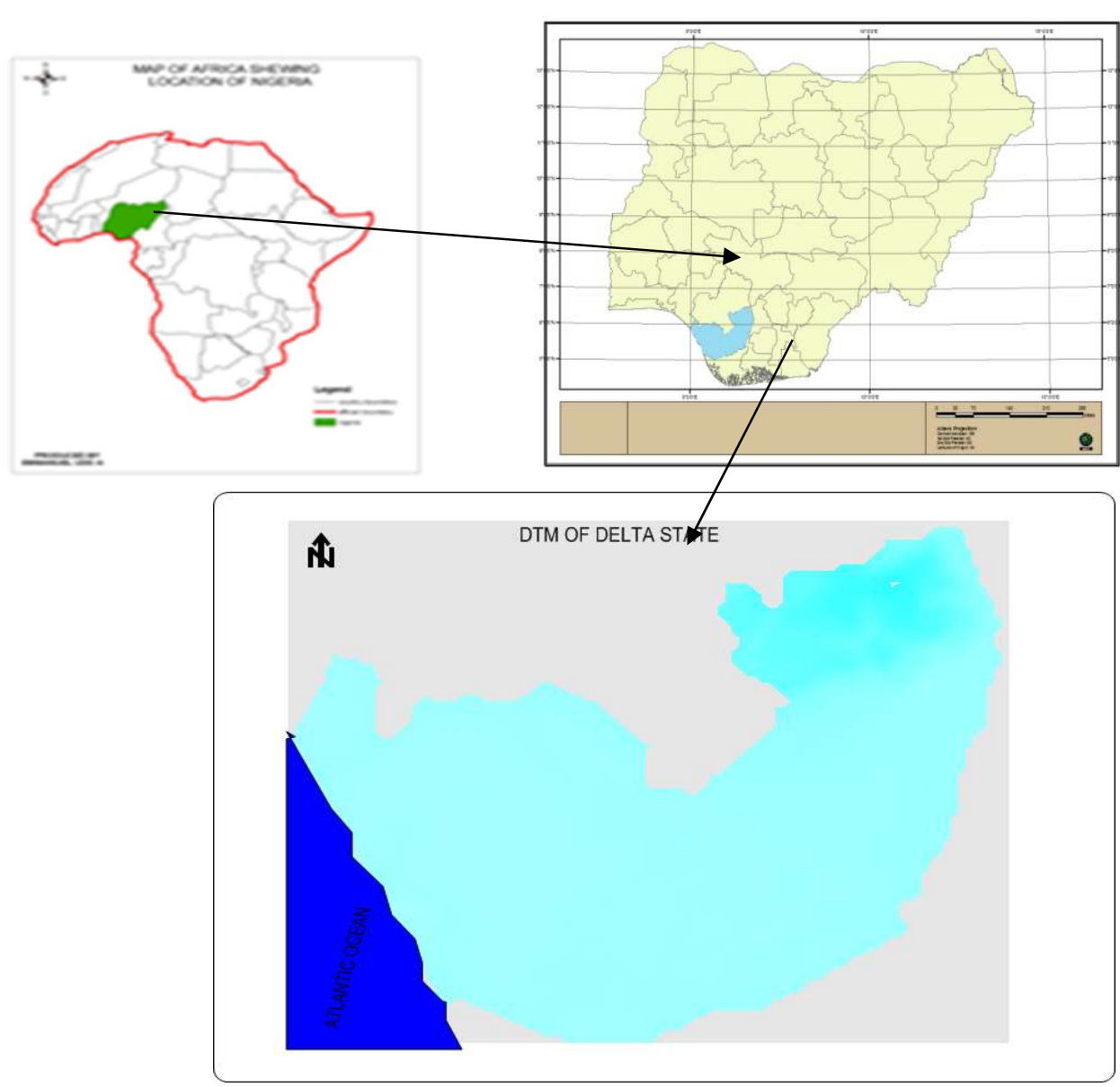

Fig 2 Location Map of The Study Area

\subsection{Materials and Methods}

The data and materials used in this study includes; SRTM of $30 \mathrm{~m}$ resolution which was downloaded from USGS site, prior and during 2012 flood remote sensing satellite imageries captured by moderate resolution imaging spectroradiometer (MODIS), Administrative map of the study area and $30 \mathrm{~m}$ resolution LANDSAT satellite imagery. GPS and notebook were also used to acquire and record the coordinates of the inundated communities respectively. Others are information gathered from NIMET, NEMA, NIWA, publications and through social survey. Software used includes ArcGIS 10.1, and ERDAS IMAGINE.

\subsection{Flood Extent Mapping}

The time series MODIS data and administrative map of the study region were each added to Arc-GIS 10.1 window and geo-referenced to WGS84 ZONE 32 coordinate system. Feature of interest were defined in Arc-Catalog extension and added as shape-files in ArcGIS environment where they were extracted as layers through digitizing. Digitizing is the process of converting geographical features from analogue or raster map into vector format. The true spatial extent of the river channel was extracted from pre-disaster imagery as polygon (shape file) and in the same process, the flood extent along the river channel from the disaster image was also digitized as polygon feature type. The map generated from the non-flood image was used as a yardstick to determine the extent of flooding (fig3). The original Extent of the river and flood layer are represented on blue and red respectively. For detail investigation, the Niger River layer and the flood mask layer were both overlaid on the administrative map layer which is disaggregated to the LGA level (Figure 3.1b). Spatial erase was carried out on the new map to erase the river feature that falls within the area of the flood polygon this also removed the true width of the Niger River from the area affected by flood. Through GIS manipulation the inundated areas were identified and mapped out. This study revealed that the submerged area along the river basin measures $2185 \mathrm{Sq} . \mathrm{kms}$. The overlay analysis 
revealed that 8 local governments were affected with Ndokwa East LGA as the most affected region (Fig3.1c)

\subsection{Terrain Modeling}

Topographical analysis was also made with a view of investigating the influence of elevation on the flood spread. The tiles of the elevation raster (SRTM) were added to ArcGIS 10.1 window. Progressively, the DEM tiles were misaicked using data management module. The misaicked raster was subjected to void filling and subsequently, transformed from geographic coordinate system to projected coordinate system (i.e. from GCS-WGS1984 to WGS1984 World Mercator. Using the boundary shape file, the study area was clipped out to the actual boundary limit and shape. The clipped DEM was processed to contour map and DEM. Progressively, the river and flood layer were superimposed on the digital elevation model created. (fig3b)

\subsection{Land Use}

The land use of the study area were extracted from the LANDSAT imagery using un-supervised image classification method. The image tiles covering the study area were added to ERDAS Imagine window and mosaicked using the Mosaic Tool. The misaicked raster was later classified using un-supervise classification algorithm. Ground truthing was embarked on in other to assign the proper LULC categories to the various classes. The classified image was exported to ArcGIS10.1 environment and transformed from geographic coordinate system to projected coordinate system (i.e. from GCS-WGS1984 to WGS1984 World Mercator). Progressively the feature classes were defined and vectorised as layers. The flood layer was superimposed on the land use classes and the extent of inundation on the various classes were digitized and calculated using calculate geometry extension (fig $3.1 \mathrm{c}$ )

\subsection{Results and Discussions}

\subsection{Results}

Figure 3.1a flood map of the study area. The original extent of the river is shown on blue while the flood mask is shown on red Fig 3.1b is the overlay analysis of river layer and flood layer on the administrative elements of the study area. fig3.1c is the area of land in square kilometers inundated at different locations within the study area. Fig3.2 is facilities damaged by the flood.. Figure3.3a and b are the, contour map and overlay analysis of river (blue) and flood mask (red) layers on Digital elevation Model (DEM) of the study area. Fig 3.4 is overlay analysis of flood mask layer (red) on land use map of the study area. Table1 shows the extent of land occupied by land use categories and the proportion of each category affected by flood within the study area.

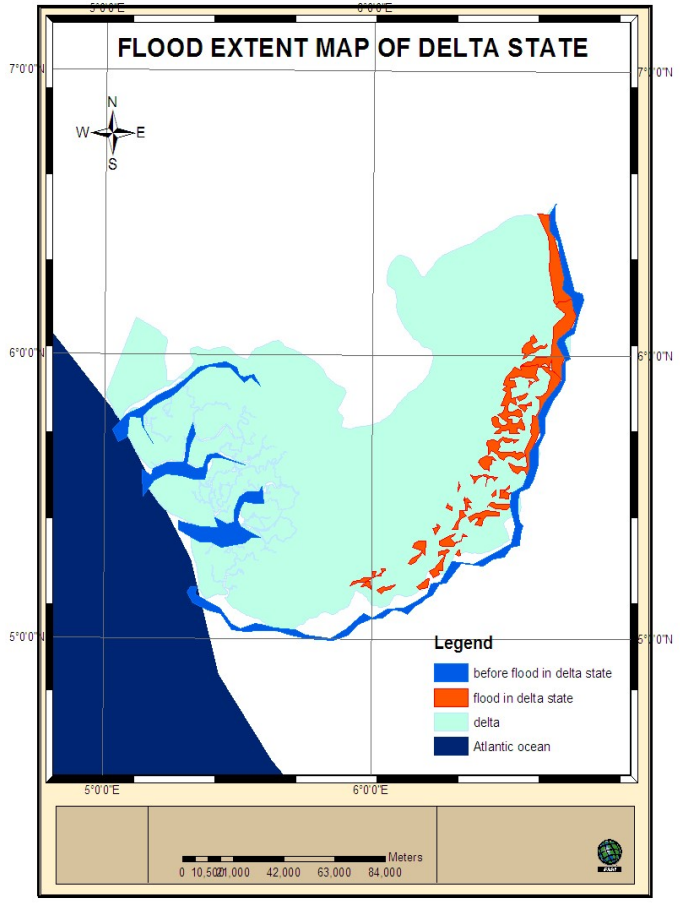

Fig 3.1a

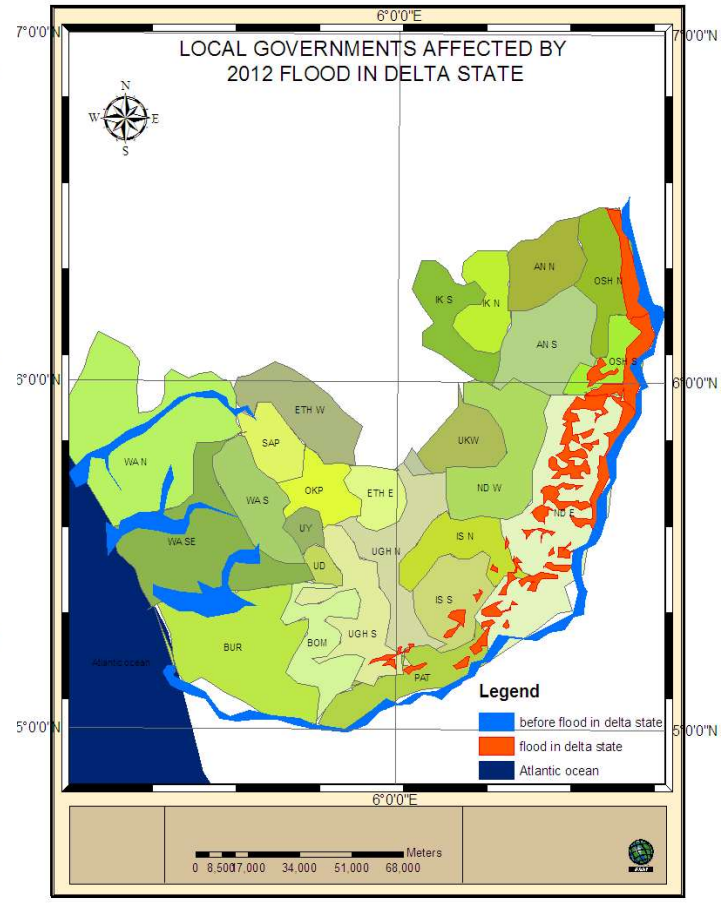

Fig 3.1b

Fig3 Overlay analisis of river layer, flood mask layer and Administrative Elements of the study area 


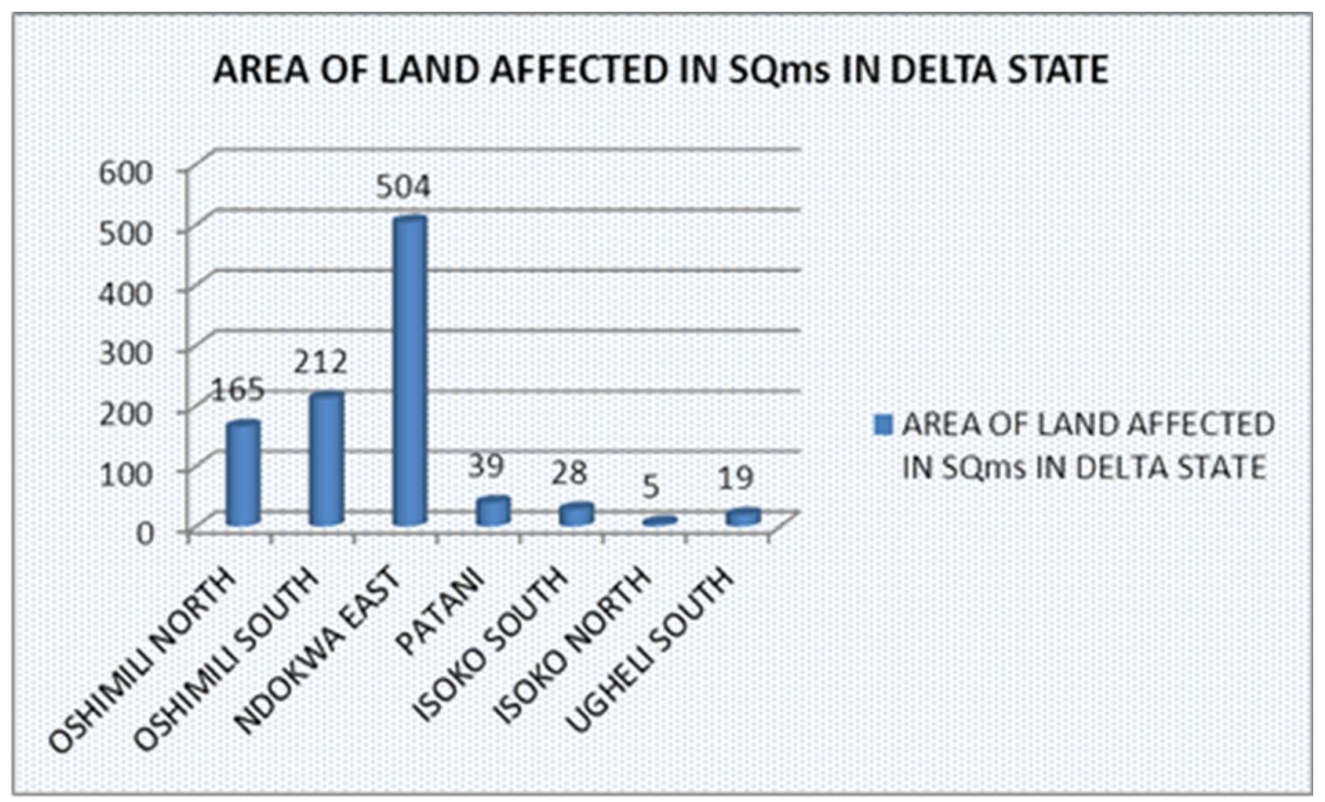

Fig3.1c extent of damage on different location within the study area

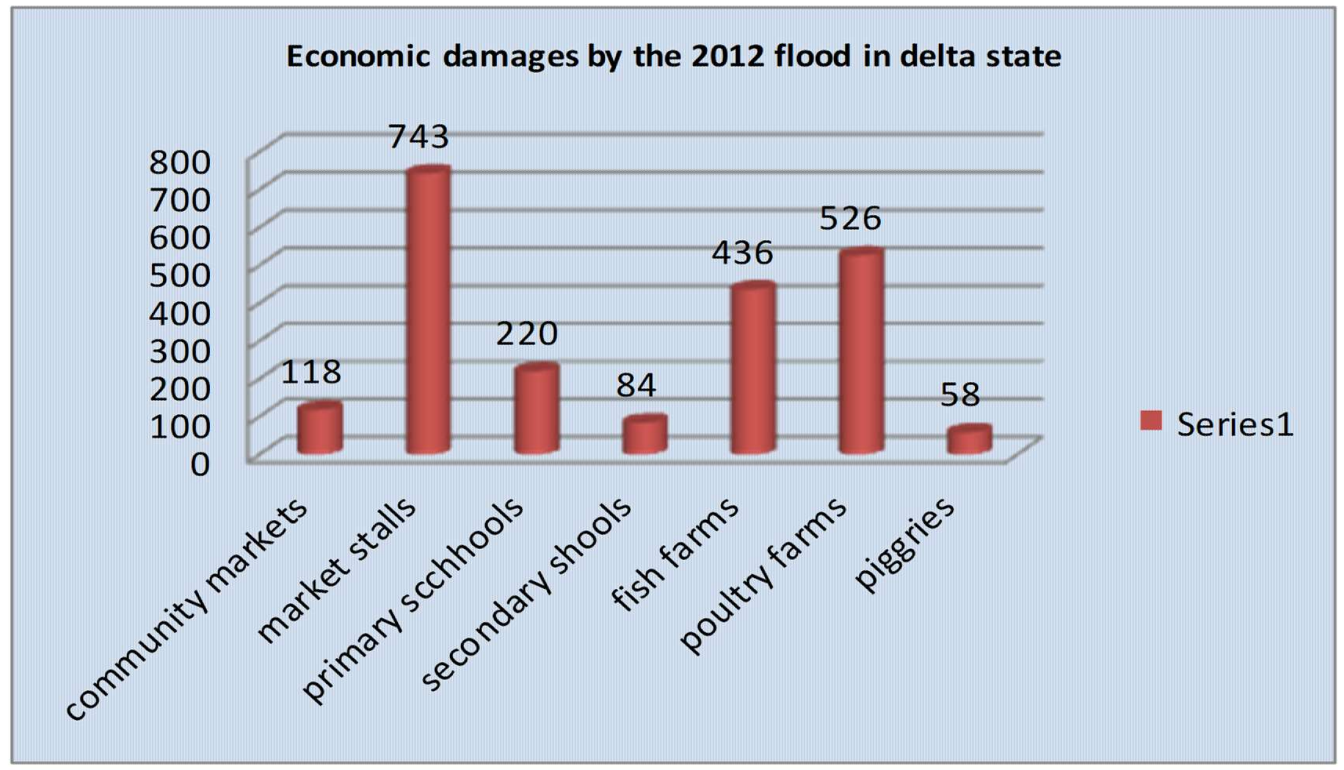

Fig3.2 extent of damage on different location within the study area 


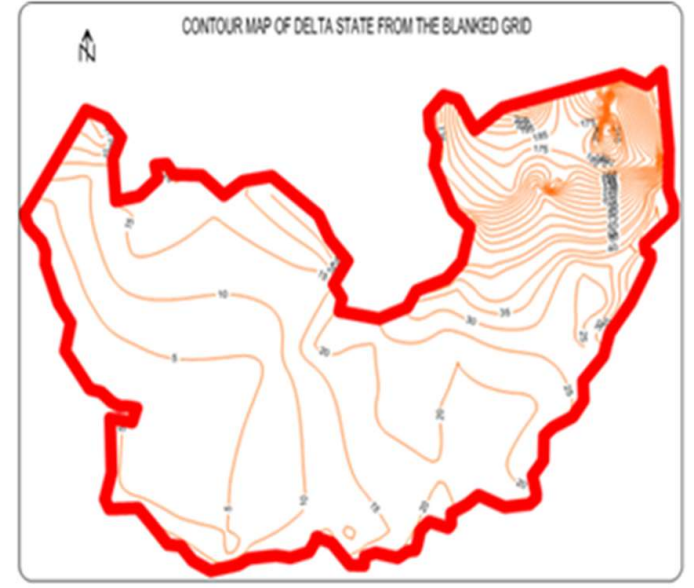

Fig3.3a contour map of the study area

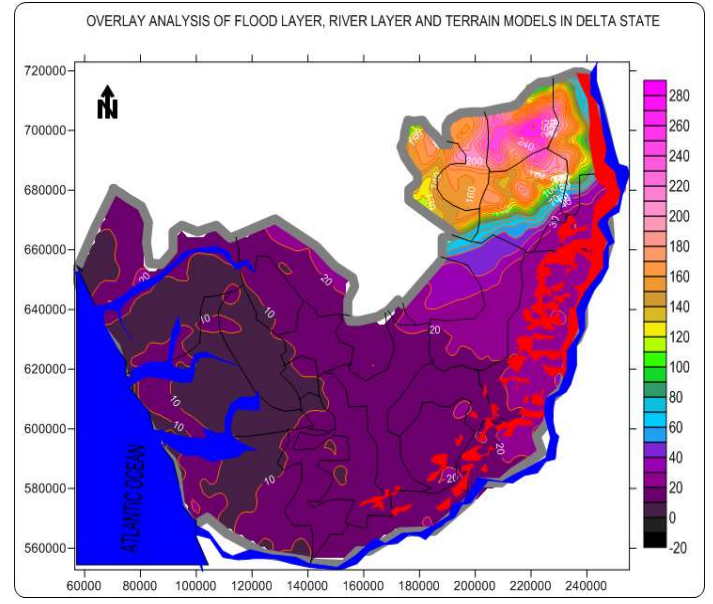

Fig3.3b Overlay analisis of river and flood layers on DEM of the study area,

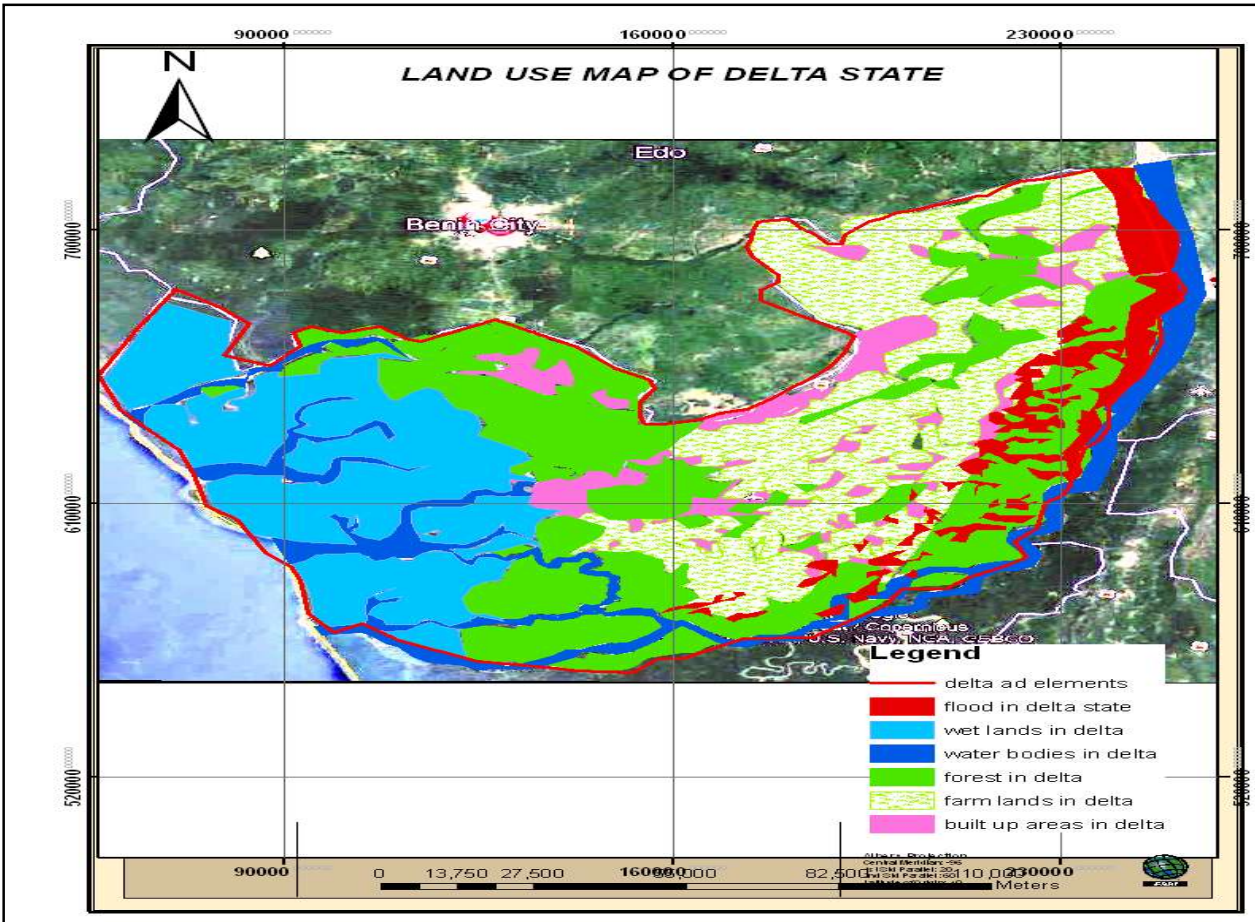

Fig 3.4 overlay analysis of flood mask layer (red) on land use of the study area. 
Table 1 Area of land occupied by land use categories and the proportion of each category affected by flood

\begin{tabular}{|l|c|c|c|}
\hline $\begin{array}{c}\text { LAND USE LAND } \\
\text { COVER }\end{array}$ & $\begin{array}{c}\text { AREA OF LAND } \\
\text { OCCUPIED } \\
\text { IN km }\end{array}$ & $\begin{array}{c}\text { PERCENTAGE OF } \\
\text { LAND OCCUPIED BY } \\
\text { LAND USE TYPES }\end{array}$ & $\begin{array}{c}\text { AREA OF LAND USE } \\
\text { AFFECTED BY 2012 } \\
\text { FLOOD IN KM }\end{array}$ \\
\hline BUILT UP AREAS & 1581.540 & 9.02 & 47.208 \\
\hline FOREST AREAS & 5693.163 & 32.48 & 768.643 \\
\hline $\begin{array}{l}\text { AGRICULTURAL } \\
\text { LANDS }\end{array}$ & 4696.147 & 26.79 & 156.149 \\
\hline WATER BODIES & 1846.714 & 21.18 & \\
\hline WET LANDS & 3712.437 & 10.54 & \\
\hline
\end{tabular}

\subsection{Discussion of result}

\subsubsection{Spatial and Economic Impact}

This study revealed that area of land along the river basin submerged measures $2185 \mathrm{Sq} . \mathrm{kms}$ and this constitute $12.46 \%$ of the land mass of the study area. The overlay analysis of flood layer on administrative element of the study area revealed that 8 local governments were submerged. In terms of spatial spread Ndokwa east was the highest affected with 504 square kilometer of its land submerged. This is followed by Oshimili South and Oshimili North L.G.A's with 202square kilometers and 165 square kilometers of their land mass submerged respectively. Other areas include Pathani, Isoko South, Ugheli South and Isoko North LGA's having 39 square kilometers, 29 square kilometers, 19 square kilometers and 5 square kilometers of their land mass submerged respectively. Investigation also revealed that 118 community markets, 743 market stores, 220 primary schools, 84 secondary schools, 436 fish farms, 526 poultry farms, and 58 piggery farms were adversely affected. It further revealed that the affected areas are low lying areas with elevation range of between $0 \mathrm{~m}$ to $40 \mathrm{~m}$ relative to the mean sea level

\subsubsection{Influence on Land Use}

This study revealed that there are five land use classes within the study area. It further revealed that Built up areas occupied $1581.540 \mathrm{sqkm}(9.02 \%)$, Forest areas occupied 5693.163sqkms (32.48\%), Farm land, water bodies and wet land occupied 4696.147sqkms (26.79\%), 1846.714sqkms2 (21.18\%) and $3712.437 \mathrm{sqkms}$ $(10.54 \%)$ of the land mass respectively. The highest affected land use is forest land followed by agricultural land and least is built up areas with 768.643 sq.kms, 156.149 sq.kms and 47.208 sqkms of these land use categories affected respectively.

\subsection{Conclusion}

This research work has shown clearly that integration of Geographic Information System and remotely sensed data is vital in geospatial analysis of flood related problems. Flood mapping products needs to be quickly available and easy to interpret by the end users. For Delta state, like many other coastal communities, floods are responsible for significant damages over large areas every year including loss of human lives and economic impacts. The use of remote sensing data adds significantly to ground observations in GIS platform are able to offer a real time updated cartographic products of the flooded area land cover and land use. The products obtained with the methodology described above provided the decision makers with accurate and comprehensive thematic maps at various spatial scales containing the extent of the flooded areas and the affected zones in near real-time. The method of satellite data processing and interpretation for the analysis of flooding is currently invoked. The integration of remote sensing and GIS has become accepted worldwide based on the fact that it provides accurate, reliable and quick spatial information needed for informed decision making. Flooded areas in Delta state has been successfully modeled, map showing the extent of land use affected and the elevation range of flooded areas within the study area has been delineated and the impact on economic activities is also identified. It was recommended that policy makers and all stake holders concerned in disaster management should adopt this reliable technique for disaster management. Also flood monitoring and management should be encouraged and funded by government and non- governmental organizations.

\section{References}

Emmanuel Udo A., Ojinnaka O. C (2015) Flood Hazard Analysis And Damage Assessment Of 2012 Flood In 
Anambra State Using GIS And Remote Sensing Approach “American Journal Of Geographic Information System” 4(1): $38-51$

Ejikeme, J.O Igbokwe, J.I Ezeomedo, I.C Aweh, D.S and Akinroye, R ( 2015 ) Analysis of Risks and Impacts of Flooding with Satellite Remote Sensing Journal of Environment and Earth Science, Vol.5, No.4,

Felix Ndidi Nkeki (2013). Geospatial Techniques for the Assessment and Analysis of Flood Risk along the Niger-Benue Basin in Nigeria, Journal of Geographic Information System http://dx.doi.org/10.4236/jgis.2013.

Hodo inyangorok (2011). “A GIS Based Flood Risk Mapping of Kano City Nigeria” school of Environmental sciences, University of East Anglia, paper NR47TJ.

Kwak, Y. and Kondoh, A. (2008) "A Study on the Extraction of Multi-Factor Influencing Floods from RS Image and GIS Data: A Case Study in Nackdong Basin, S. Korea”. The International Archives of the Photogrammetry, Remote Sensing and Spatial Information Sciences, ISPRS Congress Beijing 2008, 37, Part B8, Commission VIII, Pages 421-426

Nwafor A.N, (2006) Flood Extent Mapping In Bayesa State, Naigeria. Journal of Geography, Vol. 8 (33), pp 182

Olajuyigbe, E A, (2012) Mapping And Analysis Of 2012 Flood Disaster In Edo State Using Geospatial Technic. Journal Of Environmental sciences, vol. 6 (5), PP 32-44.

Ologunorisa, E. T. (2004). An Assessment of Flood Vulnerability Zones in the Niger Delta, Nigeria. International Journal of Environmental Studies, Vol. 61(1), pp. 31-38.

Owais Bashir, Tahir Ali, D Ram, GH Rather, Nageena Nazir, QAH Dar and Perminder singh (2019). Application of GIS in determination and mapping of topographic characteristics of temperate Himalaya. International Journal of Chemical Studies 7(2): 1092-1097

Steve Ramnoop (I995); "Flooding Analysis Strategy" Department of Mathematics and Physics, Troy University, Troy, Alabama, US 